\title{
Parental Psychosocial Well-Being as a Predictor of the Social Competence of a Child
}

\author{
Venla Panula $\mathbb{1}^{1} \cdot$ Niina Junttila $\mathbb{1}^{1} \cdot$ Minna Aromaa $^{2,3} \cdot$ Päivi Rautava ${ }^{3,4} \cdot$ Hannele Räihä ${ }^{5}$
}

Published online: 20 August 2020

(c) The Author(s) 2020

\begin{abstract}
Our study examined the interrelations between the psychosocial well-being of parents at the time of pregnancy and the social competence of their three-year-old child. Whereas most previous studies have linked the psychosocial well-being of one parent to the social development of their child, newer research has highlighted the importance of examining the psychosocial well-being of both parents and its' effects to the development of the child. This study used data from the Steps to the Healthy Development and Well-being of Children follow-up study (The STEPS Study, $n=1075$ ) to examine the interrelations between the psychosocial well-being of both the mother and the father during the period of pregnancy and the social competence of their three-year-old child. The interrelations between the psychosocial well-being of one parent and the social competence of their child were studied with regression analyses, and family-level interrelations were modeled with a latent profile analysis of family-level psychosocial well-being. At the dyadic level, the poorer psychosocial well-being of one parent during the pregnancy period mostly predicted poorer social competence in their child. However, at the family level, these links were not statistically significant. The higher level of psychosocial well-being experienced by one parent seemed to protect the development of the social competence of their child. This study emphasizes the need to consider the psychosocial well-being of both parents as a factor that influences the social development of their child.
\end{abstract}

Keywords Depressive symptoms $\cdot$ Loneliness $\cdot$ Marital dissatisfaction $\cdot$ Social competence $\cdot$ Social phobia

\section{Highlights}

- One parent's psychosocial well-being linked to the social competence of the child.

- At the family level, these links were not statistically significant.

- The results support the continuity of care in maternal and child health care.

It is well established in the literature that the psychosocial well-being of parents affects their parenting skills and their

Venla Panula

vspanu@utu.fi

1 Department of Teacher Education, University of Turku, Turku, Finland

2 Outpatient Clinic for Adolescents and Children, City of Turku, Turku, Finland

3 Department of Public Health, University of Turku, Turku, Finland

4 Turku Clinical Research Centre, Turku University Hospital, Turku, Finland

5 Department of Psychology and Speech-Language Pathology, University of Turku, Turku, Finland sensitivity in their parenting, which in turn influences their children's development (e.g., Dix 1991; NICHD Early Childcare Research Network 1999; Wilson and Durbin, 2010). Most of this research, though, has focused on the interrelations between the well-being of one parent and the development of their child (e.g., Goodman et al. 2011). However, it has been argued that to better understand the parental influences on the psychosocial well-being and development of children, it is necessary to discover the influence of both parents (see, Goodman et al. 2011; Wilson and Durbin 2010; Zhou et al. 2017).

The empirical study of family level influences on the well-being of children is yet in its infancy. However, some recent, though scarce, evidence supports the need to include both parents. For example, Gere et al. (2013) reported that the fathers' levels of depression moderated the connection 
Fig. 1 The theoretical framework of the current study

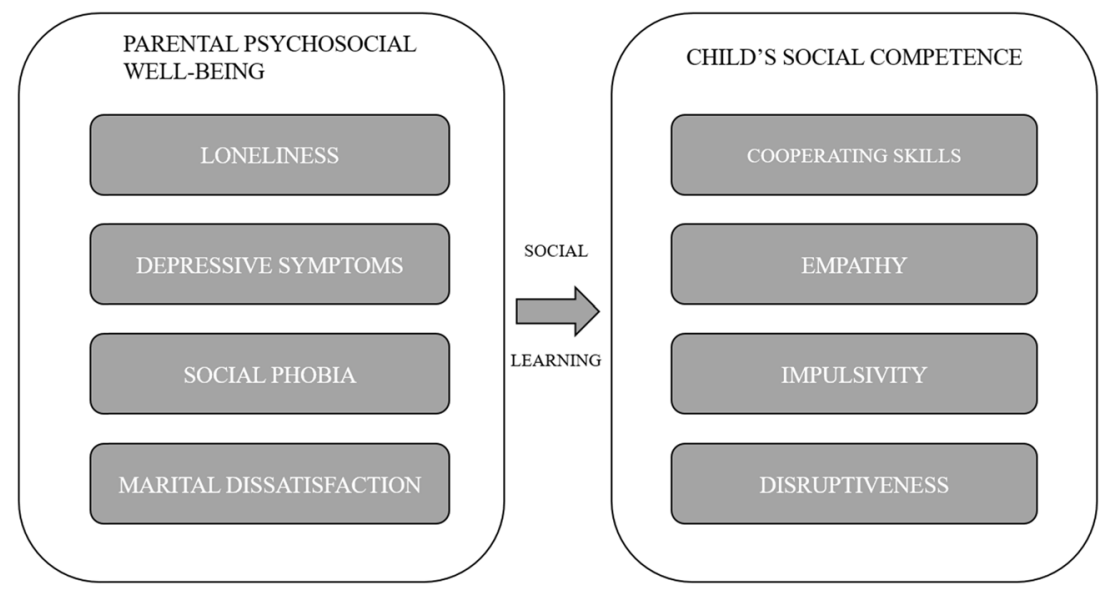

between maternal depression and the depressive symptoms of the child. In other words, better adjustment by the father seemed to lessen the negative consequences to the child of depression experienced by the mothers. Vakrat et al. (2018) found that the father's higher sensitivity in his parenting acted as a protective factor ("resilience buffer") of the psychological well-being of the child in families in which the mother experienced chronic depression. Furthermore, Zhou et al. (2017) studied how mother-reported inter-parental conflict related to the behavioral problems of young children. They found that inter-parental conflict during the child's first year was directly associated with the externalizing problems of children at age two (Zhou et al. 2017).

Conceptually, this study is grounded in both Bandura's (1963) and Vygotsky's (1978) seminal work, and, consequently, the relationship between parental psychosocial well-being and the social development of a child is considered according to the concepts of social learning and sociocultural theory. Based on Bandura's writings (e.g., Bandura 1963; Bandura and Walters 1963), social learning is a process in which an individual learns new skills and behaviors by observing a model who does a task and reproducing the model's behavior. Bandura (1963) posed that children adopt different kinds of skills and behaviors, like performing certain chores in the household or even aggressive behavior, from their parents or other influential adults. Gariépy et al. (2014) have stated that humans especially learn skills and behavior patterns from familiar individuals like parents, and younger individuals learn from adults. Williamson et al. (2013) found that already twoyear-old children learned prosocial skills by observing an adult perform new prosocial behavior. In addition, Vygotsky's sociocultural theory describes the cultural development of the child as occurring on two planes: first on the social plane between people and then on the psychological plane within the child him/herself (Wertsch 1985). So, the child learns through his/her social interactions with other people, and with time, these functions become a part of the child's intrapsychological functions. In the present study, the family is considered as the sociocultural context of the growing child, in which he/she learns how to act in social situations.

The quality of the parent-child interaction and the behavior of parents in both the parent-child relationship and the family context strongly affect the early social development of the child (e.g., Bandura 1963; Bandura and Walters 1963; Hay and Cook 2007). The parental psychosocial wellbeing is important during the first years of the child's life, since the child begins to develop social skills during infancy and toddlerhood (Hay and Cook 2007). According to Hay and Cook (2007), parents' high levels of depression and anxiety affect the prosocial development of their toddler.

In our study, we defined the psychosocial well-being of a parent by the experiences of loneliness, depressive symptoms, social phobia, and marital dissatisfaction. These experiences were considered central factors in defining parental psychosocial well-being and in sculpting the family context and the growth environment of the children (the social plane in the sociocultural theory; Wertsch 1985). As evidenced in earlier research (e.g., Dix 1991; Goodman et al. 2011; NICHD Early Childcare Research Network 1999; Wilson and Durbin 2010; Zhou et al. 2017), all these factors influence how the social competence of the child develops as he/she grows. The theoretical framework of the current study, which is depicted in Fig. 1, was based on the interrelations of these four separate factors of parental psychosocial well-being, and their influences on the social competence of the child. Next, we discuss these factors in more detail.

Loneliness is defined as a perceived lack of desired social relationships, that is, there is a discrepancy between one's actual and one's desired social relationships (e.g., Heinrich and Gullone 2006; Junttila 2010; Rotenberg 1999). In the current study, the experience of loneliness was comprised of two factors based on Weiss's original typology: social and emotional loneliness (Weiss 1973). Social loneliness results 
from the (perceived) lack of a social network, while emotional loneliness is the result of the perceived lack of a close, intimate social relationship (e.g., DiTommaso and Spinner 1997; Hoza et al. 2000; Junttila and Vauras 2009; Weiss 1973).

Depressive symptoms, which often co-occur with loneliness (e.g., Nolen-Hoeksema and Ahrens 2002), include a depressed mood, loss of interest in most activities, appetite and sleep disturbances, and feelings of worthlessness (see Richards 2011, for a review). The prevalence of maternal prenatal depression ranges between 10 and 25\% (Accortt et al. 2015), and the prevalence rates of paternal prenatal depression are similar to those of mothers (Field 2017; Gentile and Fusco 2017).

Social phobia often co-occurs with depression (e.g., Ranta 2008). Social phobia includes experiences of fear, avoidance behaviors, and physiological discomfort in social situations (Connor et al. 2000). In addition to these cooccurring phenomena, marital dissatisfaction is also connected to poorer psychosocial well-being (e.g., Hawkley et al. 2008; Whisman 1999). Marital satisfaction or dissatisfaction is defined as either a balance or an imbalance of the benefits and costs of marriage to the person in question (Stone and Shackelford 2006). Stone and Shackelford (2006) also mention that the marital dissatisfaction of one person often correlates with the emotional instability of their spouse.

The interrelations between these co-occurring phenomena have been well documented in previous research. For example, loneliness was found to be associated with anxiety and depression (e.g., Hagerty and Williams 1999; Heinrich and Gullone 2006; Muyan et al. 2016; Victor and Yang 2012). Considering loneliness and the quality of marital relationships, emotional loneliness was found to explain $40 \%$ of the variance in the quality of the marital relationship (Knoke et al. 2010). Based on Knoke et al. (2010), the ability of marriage to protect against loneliness seems to lie in the quality of the marital relationship. Hawkley and colleagues (2008) concluded that when a person considered their spouse as a confidant (with whom one could share important matters or who were a source of support), being married was negatively associated with loneliness. However, when a spouse did not serve as a confidant, marriage did not protect against loneliness any better than not being married (Hawkley et al. 2008). Regarding the loneliness experienced by parents, Junttila et al. (2015a) found that mothers who experienced social or emotional loneliness had more feelings of marital dissatisfaction, social fears, and depressive symptoms in comparison with mothers who did not experience loneliness.

The psychosocial well-being of the parents already during pregnancy affects the environment in which their children grow and develop. Considering the pregnancy period specifically, prenatal depression was reported to affect the maternal-fetal emotional bonding (Seimyr et al. 2009). In addition, for mothers, prenatal depression symptoms were associated with distorted prenatal representations of the unborn child and for fathers, marital dissatisfaction had the same effect (Ahlqvist-Björkroth 2017). In a previous study Nolvi et al. (2016) reported that maternal prenatal stress (defined as stress, anxiety, and pregnancy-specific anxiety) was associated with higher negative reactivity in infants. These effects were not mediated by the reported postnatal issues in mental health, which suggests the prenatal period plays a unique role in child behavior (Nolvi et al. 2016). Previous studies have also confirmed that both loneliness and depressive symptoms experienced by the parents show quite strong stability over time from the pregnancy period to the first postpartum years (Beck 2001; Junttila et al. 2015a; Paulson et al. 2016). Marital relationship has been reported as a predictor of postpartum depression for mothers (Beck 2001), but studies reporting these associations for fathers are yet scarce.

In early childhood, a key aspect of children's development is the development of social competence. Social competence is defined as the skills and knowledge that a person needs to act appropriately in social settings and to create and maintain meaningful social relationships (e.g., Anderson-Butcher et al. 2008; Burt et al. 2008). What exactly comprises the social competence of children varies according to age, since children of various ages have different social needs. The ways to interact with peers, to be part of a group, and to create meaningful relationships with others differ according to the age of the children and the culture to which they belong (e.g., Rubin et al. 2006).

Generally, social competence can be divided into two behavioral types: prosocial behavior and the absence of antisocial behavior (e.g., Tremblay 2005). Prosocial behavior involves socially desirable actions, like helping, sharing, or cooperating with others (Junttila et al. 2006). Antisocial behavior is described as impulsive or disruptive behavior that has negative social outcomes (Junttila et al. 2006). The prosocial development in early childhood progresses from passive participation to cooperative playing and problem solving, and from compliance to sharing and attempting to comfort others (Hay and Cook 2007). In early childhood children's play becomes more complex and they learn how to communicate, negotiate and compromise in social relationships (Aldercotte et al. 2016). As social competence develops in early childhood, it manifests as positive interactions with others as well as learning how to regulate one's emotions (e.g., Rose-Krasnor and Denham 2009). Social competence in childhood was found to be negatively related to internalizing symptoms in adolescence (Burt et al. 2008). In other words, having the right skills to interact with peers in a positive manner during childhood yields a higher level of well-being later in life. 
Parents' problems with psychosocial well-being can affect their parenting skills, particularly, the ways in which the parents interact with their children (e.g., Dix 1991; Wilson and Durbin 2010; Kertz et al. 2008). In turn, the parenting skills and the quality of the parent-child interactions influence the growth environment that the parents create for their children. For instance, the parents' experienced symptoms of social anxiety or social phobia are interrelated with their child's behavioral and emotional development and with the ways in which the parents interpret their child's skills and development. Parents diagnosed with social anxiety disorder displayed less positive affect and more criticism of and doubts about their child's competence than did parents who did not have a current social anxiety disorder diagnosis (Crosby Budinger et al. 2013). In addition, the antenatal anxiety of a mother strongly predicted the behavioral and emotional problems of her child at age four (O'Connor et al. 2002).

Regarding depressive symptoms, previous studies have established links between the prenatal or perinatal depression of both mothers and fathers and the emotional, behavioral, and developmental problems in their children (Field 2011; Gentile and Fusco 2017; Jacobs et al. 2015). Maternal depressive symptoms have been found to predict poorer adjustment (e.g., lower social competence and more behavioral problems) during the first three years of the child's life, and especially poor adjustment when the child experienced high negative emotionality as an infant (Dix and Yan 2014). Wang and Dix (2015) studied the interrelations between the depression of mothers and the social competence of children, finding that a mother's depression during the first years of her child's life predicted that her child would have lower social competence when he/she was seven years old. The depression of parents, especially mothers, seems to be an important factor affecting the development of their child in infancy and toddlerhood.

In addition to parental depression, which causes negative consequences, being raised in a socially isolated family was suggested to be a risk factor for the occurrence of loneliness experienced by children (Solomon 2000). Considered from the perspective of the social learning theory, children in these families have fewer possibilities to learn appropriate behavior in social situations (Solomon 2000; Lawhon 1997). Since social competence is a skill one uses to create and maintain meaningful relationships with others, not having many experiences of participating in social situations may hinder the development of the social competence of a child. A previous study also found that the higher marital satisfaction of mothers predicted a better quality of family interaction between the mother, the father, and their child (Korja et al. 2016). Negative outcomes in the developing social competence of children may not only be caused by problems with parental well-being but may also be a result from different interactions between parents and their child.

Our study aimed to offer new insight into the familylevel interrelations between parental psychosocial wellbeing and the social competence of their child, and to further support the importance of simultaneously studying dyadic- and family-level influences. Specifically, we explored the relationship of the psychosocial well-being of parents at the family level and the very early development of the social competence of their children. A unique feature of the present study was its focus on very young children (aged three years) in relation to the psychosocial well-being of their parents, the starting point for this data predating the child's birth. To our knowledge, no other similar empirical studies exist. To achieve a more comprehensive view of these influences both at individual parent and family level, three research goals were established: (1) to investigate if the psychosocial well-being of one parent during the period of pregnancy affected the social competence of their threeyear-old child, (2) to examine the parental psychosocial well-being at the family level using latent profile analysis, and (3) to study whether these family-level profiles of psychosocial well-being, which were measured during the pregnancy period, were associated with the social competence of their three-year-old child.

The dyadic relations between one parent and the child, based on the theory of social learning and previous studies, informed the hypothesis that parental psychosocial wellbeing would predict the level of the social competence of their child, so that reported problems in the psychosocial well-being of parents would result in less socially competent children. At the family level, problems in parental psychosocial well-being were assumed to accumulate, so that the latent profile analysis would show a profile of families in which both parents reported high levels of problems on all measures of psychosocial well-being. These family-level profiles of parental psychosocial well-being were also expected to create statistically significant differences in the social competence of the children.

\section{Method}

\section{Participants}

This study is based on data from a longitudinal cohort study of children and their parents, the Steps to the Healthy Development and Well-being of Children (The STEPS Study, described in detail in Lagström et al. 2013). All mothers who delivered a living child between January 1, 2008 and April 31, 2010 in the Hospital District of Southwest Finland, together with their children, formed the cohort population (9811 mothers and 9936 children). Of this 
cohort, a total of 1797 mothers, 1827 children, and 1658 partners volunteered as participants in the intensive followup group of the STEPS study. Families were recruited during the first trimester of pregnancy (1387 mothers) or after delivery in the delivery wards (410 mothers). The parents recruited after deliveries were not included in these analyses. The data for the present study were collected with detailed questionnaires answered by mothers and fathers during the 20th week of gestation.

For the present study, we chose to use the data collected from couples; that is, our research sample included only families in which both the mother and the father were present and answered the questionnaires. First, the families with complete missing data from either one or both parents at the first measurement point (the 20th week of gestation) were excluded, as well as families with twins as the focal children in the STEPS study. Then the criteria for sample selection were (1) marital status (the parents were married or cohabiting) and (2) family structure (the mother and the father lived together). Thirty mothers reported being either single, divorced/separated, widowed, or in a registered partnership, and they were excluded based on their reported marital status. An additional six mothers reported living without a spouse. These families were also excluded from the sample to avoid the possibility of including single parents in the analyses. Our final research sample included 1075 families: mothers, fathers, and children. The mean age of mothers was 30.4 years and the mean age of fathers was 32.4 years. Of the mothers, $52.8 \%$ were expecting their first baby. The STEPS study was directed to Finnish and/or Swedish speaking families, and as a result over $90 \%$ of both mothers and fathers reported having Finnish as their first language. Swedish, which is the second official language of Finland, was the first language of $4.8 \%$ of the mothers and of $6.2 \%$ of the fathers. The study sample resembles the Finnish population of which approximately $5 \%$ are Swedish-speaking Finns. More precise information on the ethnic background of the participants was not collected. $59.7 \%$ of the mothers and $43.4 \%$ of the fathers had completed at least one degree in higher education, and $32.0 \%$ of the mothers and $44.0 \%$ of the fathers had finished upper secondary school. $4.8 \%$ of the mothers and $7.7 \%$ of the fathers reported only having finished comprehensive school. Regading household income, $48.1 \%$ of the mothers estimated their combined monthly net income of the household to be $3000 €$ or more. $2.6 \%$ of the mothers reported their household to have their monthly net income less than $1000 €$. Among the children, $50.4 \%$ were boys. When the children were 3 years old, 403 of them were being cared for outside the home and 225 were in home care. Of the children in day-care settings outside the home, $45.7 \%$ were in day-care centers operated by the municipality, and others in either private day-care centers $(16.4 \%)$, or family day-cares ran by the municipality $(26.8 \%)$ or by private organizations $(9.7 \%)$. A small number of children $(1.5 \%)$ was being cared for outside the home by grandparents or other relatives. The information of the form of day-care was missing from 447 children.

Comparing the chosen study sample and the group of excluded cases revealed that the estimation of their combined monthly household income was statistically significantly smaller in the excluded group than in the study sample $(p<0.01)$. In the excluded group, the education level of both mothers and fathers was also lower than in the chosen study sample $(p s<0.01)$. In addition, mothers in the excluded group reported poorer psychosocial well-being. The excluded mothers reported statistically significantly more social and emotional loneliness, social phobia, and depressive symptoms than mothers in the study sample (all $p s<0.05$ ). The excluded mothers also reported more marital dissatisfaction. Since the exclusion was based on marital status and/or family structure, this could explain the differences between the two groups at least in the scores of marital dissatisfaction, but possibly in the other measures, too.

The exclusion criteria (mothers either single and/or living alone) also resulted in a very small number of fathers in the excluded group $(n=42)$. These were the fathers who lived separated from the mothers at the first measurement point. The fathers in the excluded group reported statistically significantly more social loneliness than fathers in the study sample $(p=0.03)$. In all other measures of psychosocial well-being, the differences between the two groups of fathers were not statistically significant.

\section{Procedure}

The Ministry of Social Affairs and Health as well as the Ethics Committee of the Hospital District of Southwest Finland approved the STEPS study (February 27, 2007). The parents signed a written informed consent. They were informed of their right to withdraw from the study at any point. The description of the scientific data file has been formulated according to the standards of the Office of the Data Protection Ombudsman. The data are stored under lock and key on computers at the Turku Institute for Child and Youth Research, University of Turku.

In our study, psychosocial well-being consisted of experiences of social and emotional loneliness, depressive symptoms, social phobia, and marital dissatisfaction. The measures of parental psychosocial well-being were collected during the 20th week of gestation. The validity and reliability of the parental measures have been presented in more detail in previous articles (Junttila et al. 2015a, 2015b). The measure of the social competence of the children consisted of four factors: (1) cooperating skills and 
(2) empathy, which portrayed prosocial behavior, and (3) impulsivity and (4) disruptiveness, which portrayed antisocial behavior.

\section{Measures}

\section{Loneliness}

Russell et al.'s (1980) Revised UCLA Loneliness Scale is widely used and has well-established reliability and validity in different contexts (see, e.g., Hojat 1982; McWhirter 1990; Pretorius 1993). The scale was validated in the Finnish context and it consists of factors of social and emotional loneliness (Junttila et al. 2013). Social loneliness is measured with six items, utilizing the absence of a social network or feelings of not belonging (e.g., "I feel shut out and excluded by others."). The factor of emotional loneliness was also measured with six items that emphasize the importance of a close social relationship (e.g., "I am no longer close to anyone."). The items were measured on a four-point Likert scale (1-4), which indicated how often the participant experienced these feelings (never, rarely, sometimes, and often). The minimum score for both factors was six and the maximum (estimating the utmost feelings of loneliness) was 24. For the whole STEPS Study sample, the Cronbach's alphas for mothers and fathers were respectively $0.79 / 0.77$ for social loneliness and $0.78 / 0.76$ for emotional loneliness.

\section{Depressive symptoms}

To assess the depressive symptoms of the mothers and the fathers, Beck's Depression Inventory (BDI-II) was adopted (Beck et al. 1996). The Finnish version of BDI-II, which includes 21 items that were each rated on a four-point scale (0-3), was used. The items measure the symptoms and the attitudes related to depression, for example, pessimism ("I feel the future is hopeless and that things cannot improve.") and self-accusation ("I blame myself for everything bad that happens."). The sum scores range from zero (no depressive symptoms) to 63 (severe symptoms of depression). In the whole STEPS Study sample, Cronbach's alphas at the 20th week of gestation were 0.83 for mothers and 0.84 for fathers.

\section{Social phobia}

The social phobia of parents was assessed by the Social Phobia Inventory (SPIN), which is a self-report questionnaire used to measure fear, avoidance behaviors, and physiological discomfort in performance or social situations (Connor et al. 2000). SPIN has been previously validated with Finnish data (Ranta 2008). SPIN includes 17 items, with which the subjects assess how often they experienced a measured feeling or behavior (e.g., "avoids talking to strangers" and "distressed by palpitations") during the previous week. The responses were rated with a Likert scale ranging from zero (not at all) to four (extremely). The minimum score, estimating minimal feelings of social phobia, is zero, and the maximum, estimating high feelings of social phobia, is 68. During the period of pregnancy, Cronbach's alphas in the STEPS Study sample overall were 0.91 for mothers and 0.91 for fathers.

\section{Marital dissatisfaction}

To assess parents' satisfaction with their current marital relationship, we used Busby et al.'s (1995) Revised Dyadic Adjustment Scale (RDAS). RDAS is effective at distinguishing between marital satisfaction and dissatisfaction (Busby et al. 1995; White et al. 1994). 13 items in the RDAS scale assess the level of agreement or disagreement between the couple by using a six-point Likert scale, with the responses ranging from one (always agree) to six (always disagree), as well as one item on a five-point Likert scale, ranging from one to five. The themes include discussion and conflict regulation (e.g., "How often would you say you have a stimulating exchange of ideas between you and your partner?" and "How often do you and your partner quarrel?"). The minimum score, estimating the best possible marital satisfaction, is 14 , and the maximum, estimating high dissatisfaction, is 84 . At the first measurement point (the 20th week of gestation) Cronbach's alphas for the STEPS Study sample overall were .80 for mothers and .80 for fathers.

\section{Social competence}

The social competence of the three-year-old children was measured with the Multisource Assessment of Social Competence scale (MASCS), which was developed and validated by Junttila et al. (2006). The MASCS scale includes 13 items loading onto four different factors of social competence. The prosocial dimension is divided into two factors: cooperating skills (e.g., "Offers help to other children.") and empathy (e.g., "Is sensitive to the feelings of other children."). The antisocial dimension contains factors of impulsivity (e.g., "Is easily irritated.") and disruptiveness (e.g., "Acts without thinking.", see Junttila et al. 2006, for additional information). The responses are measured on a range from one (never) to four (very often). The parents (either the mother or the father, or both parents together) rated the social competence of their child with the MASCS scale when the child was three years old. Information on who in fact filled in the MASCS questionnaire was not collected. The sum scores of three factors-cooperating 
Table 1 Descriptive statistics of the parental measures at the first measurement point (the 20th week of gestation)

\begin{tabular}{llllllllll}
\hline & $\mathrm{n}$ & $M$ & $\mathrm{SD}$ & $\mathrm{n}$ & $M$ & $\mathrm{SD}$ & $t(\mathrm{df})$ & Cohen's d \\
& \multicolumn{2}{l}{ Mothers } & \multicolumn{2}{l}{ Fathers } & & & \\
\hline Social loneliness & 1063 & 9.61 & 2.69 & 1063 & 9.54 & 2.66 & $0.62(1050)$ & 0.02 \\
Emotional loneliness & 1063 & 8.76 & 2.32 & 1063 & 9.42 & 2.56 & $-7.11(1050)^{* * *}$ & 0.23 \\
Marital dissatisfaction & 1037 & 31.03 & 6.04 & 1044 & 30.80 & 5.95 & $0.85(1009)$ & 0.02 \\
Social phobia & 1059 & 8.59 & 7.75 & 1049 & 8.13 & 7.95 & $1.44(1033)$ & 0.04 \\
Depressive symptoms & 1058 & 8.91 & 5.92 & 1057 & 3.57 & 4.57 & $25.86(1039)^{* * *}$ & 0.72 \\
\hline
\end{tabular}

$* p \leq 0.05 ; * * p \leq 0.01 ; * * * p \leq 0.001$ skills, empathy, and impulsivity-range from three to 12 points; for disruptiveness, the range is four to 16 points. Cronbach's alphas for the factors of social competence in this sample were 0.75 for cooperating skills, 0.79 for empathy, 0.81 for impulsivity, and 0.71 for disruptiveness.

\section{Data Analysis Plan}

Both the mothers and the fathers completed the questionnaires at home and returned them to the research center. Research assistants coded the answers into data matrixes by using identification codes. To study the interrelations between the measures of parental well-being and the social competence of children, we used multiple linear regression analyses. To control for potential multicollinearity in the regression models, we checked the variance inflation factor (VIF) scores. Afterwards, we administered a latent profile analysis (LPA), a method of structural equation modeling. This was done to gain information on parental psychosocial well-being at the family level, as well as on the consequences of parental psychosocial well-being on the social competence of their children. The idea of the LPA as a method is to distinguish different profiles of the participants, so that the profiles are as heterogenous as possible, but at the same time participants within a profile are as homogenous as possible. This method was the most suitable one to examine the family-level psychosocial well-being.

The selection of the solution of the latent profile analyses was based on multiple criteria. First, the fit of the model was evaluated with the Akaike information criterion (AIC) and the Bayesian information criterion (BIC) (Akaike 1987). Then the distinguishability of the latent profiles was assessed with entropy values and average latent class posterior probabilities. Usually, the cutoff for a good classification of the entropy value is .80 (Wang and Bodner 2007). Latent class proportions, and the theoretical justification and interpretability of the latent profiles were also considered. The analyses were run in IBM SPSS Statistics 23 and Mplus, Version 7 (Muthén and Muthén 2013). Possible differences in the MASCS scores between the resultant latent profiles were calculated with the auxiliary option in Mplus. This was done to examine whether there was a statistically significant relation between the latent profiles and the auxiliary variables (MASCS scores).

\section{Results}

Table 1 shows the mean scores of the mothers and fathers and the standard deviations on all measures of parental psychosocial well-being at the first measurement point (the 20th week of gestation). The mean scores of the social and emotional loneliness of both the mothers and the fathers were low (9.61 and 8.76 for mothers; 9.54 and 9.42 for fathers). The low levels of marital dissatisfaction, social phobia, and depressive symptoms also indicated that, for the most part, both mothers and fathers experienced psychosocial well-being that was quite good.

$T$-tests revealed that there were no statistically significant differences in the social loneliness, marital dissatisfaction, and social phobia between the mothers and the fathers ( $p$ s $0.54,0.40$, and 0.15 , respectively). Regarding emotional loneliness and depressive symptoms, the differences between mothers and fathers were statistically significant ( $p s<0.01$ ). During the mother's pregnancy, fathers reported more emotional loneliness than mothers. At the same measurement point, mothers reported statistically significantly more depressive symptoms than fathers. In addition, the education level of the parents was associated with some measures of psychosocial well-being. For mothers, being more educated was associated with lower levels of social loneliness and social phobia (nonparametric Kruskall-Wallis tests, $p \mathrm{~s}<0.01$ ), and having a degree from higher education was also associated with lower levels of emotional loneliness and depressive symptoms, compared to mothers who had completed only comprehensive school or upper secondary school. For fathers, the associations between the level of education and the measures of psychosocial well-being were only statistically significant in emotional loneliness and social phobia, between fathers with a degree from higher education and fathers with a degree from upper secondary school. The age of the parents did not show any strong correlation with the measures of their psychosocial well-being. 
Table 2 Correlations between measures of the psychosocial well-being of mothers and fathers at the 20th week of gestation

\begin{tabular}{|c|c|c|c|c|c|c|c|c|c|c|}
\hline & \multicolumn{5}{|c|}{ Mothers } & \multicolumn{5}{|c|}{ Fathers } \\
\hline & 1 & 2 & 3 & 4 & 5 & 6 & 7 & 8 & 9 & 10 \\
\hline \multicolumn{11}{|l|}{ Mothers } \\
\hline \multicolumn{11}{|l|}{ 1. Social loneliness } \\
\hline 2. Emotional loneliness & 0.69 & & & & & & & & & \\
\hline 3. Depressive symptoms & 0.39 & 0.36 & & & & & & & & \\
\hline 4. Social phobia & 0.45 & 0.37 & 0.39 & & & & & & & \\
\hline 5. Marital dissatisfaction & 0.31 & 0.34 & 0.39 & 0.25 & & & & & & \\
\hline \multicolumn{11}{|l|}{ Fathers } \\
\hline 6. Social loneliness & 0.22 & 0.18 & 0.12 & 0.18 & 0.20 & & & & & \\
\hline 7. Emotional loneliness & 0.23 & 0.22 & 0.12 & 0.14 & 0.25 & 0.64 & & & & \\
\hline 8. Depressive symptoms & 0.16 & 0.18 & 0.21 & 0.15 & 0.20 & 0.42 & 0.40 & & & \\
\hline 9. Social phobia & 0.15 & 0.18 & 0.08 & 0.22 & 0.13 & 0.54 & 0.39 & 0.35 & & \\
\hline 10. Marital dissatisfaction & 0.15 & 0.19 & 0.21 & 0.13 & 0.58 & 0.36 & 0.43 & 0.37 & 0.26 & \\
\hline
\end{tabular}

All correlations are significant at the 0.01 level (two-tailed)
Table 3 Descriptive statistics of the social competence of the three-year-old children

\begin{tabular}{lllllllll}
\hline & $\mathrm{n}$ & $M$ & $\mathrm{SD}$ & $\mathrm{n}$ & $M$ & $\mathrm{SD}$ & $t(\mathrm{df})$ & Cohen's d \\
& Boys & & \multicolumn{7}{c}{ Girls } & & & & \\
\hline Cooperating skills & 295 & 9.26 & 1.62 & 280 & 9.68 & 1.39 & $-3.35(573)^{* * * *}$ & 0.28 \\
Empathy & 285 & 9.13 & 1.47 & 273 & 9.59 & 1.44 & $-3.76(556)^{* * *}$ & 0.32 \\
Impulsivity & 283 & 6.50 & 1.71 & 274 & 6.43 & 1.51 & $0.545(555)$ & 0.05 \\
Disruptiveness & 285 & 7.28 & 1.80 & 269 & 6.87 & 1.63 & $2.835(552)^{* *}$ & 0.24 \\
\hline
\end{tabular}

$* p \leq 0.05 ; * * p \leq 0.01 ; * * * p \leq 0.001$
Table 2 shows the correlations between social and emotional loneliness, depressive symptoms, social phobia, and the marital dissatisfaction of both the mothers and the fathers at the 20th week of gestation. The strongest correlations occurred between the social and emotional loneliness of mothers $(r=0.69)$ as well as between the social and emotional loneliness of fathers $(r=0.64)$. All presented correlations were statistically significant, with the correlation coefficients varying between 0.08 and 0.69 .

Table 3 depicts the descriptive statistics of the social competence of the three-year-old children. There were statistically significant differences between boys and girls in three of the four factors that measure social competence. Girls were rated as both having better cooperating skills and behaving more empathetically than boys ( $p s \leq 0.001)$. Boys were evaluated to exhibit more disruptive behavior than girls $(p=0.01)$. For impulsivity, the difference between boys and girls was not statistically significant. In addition, neither the education level nor the age of the parents had any statistically significant association with the reported social competence of the child.

\section{The Psychosocial Well-Being of One Parent as a Predictor of the Social Competence of Their Child}

To investigate our first aim concerning the dyadic interrelations between the psychosocial well-being of one parent during pregnancy and the social competence of their threeyear-old child, we conducted several linear regression analyses. Each regression model included one factor from the MASCS scale (cooperating skills, empathy, impulsivity, and disruptiveness) as the dependent variable and all the measures of the psychosocial well-being of the parent (social loneliness, emotional loneliness, depressive symptoms, social phobia, and marital dissatisfaction) as independent variables. The results are presented in Table 4. The VIF scores ranged between 1.25 and 2.15 for the mothers' scores, and between 1.22 and 2.16 for the fathers' scores. The VIF scores were all well within acceptable limits $(<5$; Montgomery et al. 2012), and therefore we didn't experience any issues with potential multicollinearity in the regression models.

According to the results, the reported social loneliness of both the mothers and the fathers were statistically 
Table 4 Dyadic interrelations between parental psychosocial well-being and factors of the social competence of their children

\begin{tabular}{|c|c|c|c|c|c|c|}
\hline & \multicolumn{3}{|l|}{ Mothers } & \multicolumn{3}{|l|}{ Fathers } \\
\hline & $\mathrm{F}(d f)$ & $\mathrm{R}^{2}$ & Independent measures & $\mathrm{F}(d f)$ & $\mathrm{R}^{2}$ & Independent measures \\
\hline Cooperating skills & $2.64(5,532)^{*}$ & 0.02 & $\begin{array}{l}\text { SL: } \beta=-0.16, p=0.01 \\
\text { EL: } \beta=0.02, p=0.75 \\
\text { RDAS: } \beta<0.01, p=0.94 \\
\text { SPIN: } \beta=-0.03, p=0.54 \\
\text { BDI: } \beta=0.03, p=0.57\end{array}$ & $2.26(5,530)^{*}$ & 0.02 & $\begin{array}{l}\text { SL: } \beta=-0.19, p<0.01 \\
\text { EL: } \beta=0.09, p=0.12 \\
\text { RDAS: } \beta=-0.04, p=0.41 \\
\text { SPIN: } \beta=0.05, p=0.37 \\
\text { BDI: } \beta=-0.02, p=0.70\end{array}$ \\
\hline Empathy & $3.86(5,519)^{* *}$ & 0.04 & $\begin{array}{l}\text { SL: } \beta=-0.14, p=0.03 \\
\text { EL: } \beta=-0.08, p=0.19 \\
\text { RDAS: } \beta=-0.03, p=0.61 \\
\text { SPIN: } \beta=0.02, p=0.70 \\
\text { BDI: } \beta=0.03, p=0.57\end{array}$ & $1.28(5,516)$ & 0.01 & $\begin{array}{l}\text { SL: } \beta=0.01, p=0.85 \\
\text { EL: } \beta=-0.02, p=0.77 \\
\text { RDAS: } \beta=-0.06, p=0.19 \\
\text { SPIN: } \beta=-0.05, p=0.35 \\
\text { BDI: } \beta=-0.04, p=0.48\end{array}$ \\
\hline Impulsivity & $5.21(5,515)^{* * *}$ & 0.05 & $\begin{array}{l}\text { SL: } \beta=-0.08, p=0.23 \\
\text { EL: } \beta=0.10, p=0.08 \\
\text { RDAS: } \beta=0.13, p=0.01 \\
\text { SPIN: } \beta=0.02, p=0.69 \\
\text { BDI: } \beta=0.10, p=0.06\end{array}$ & $1.48(5,516)$ & 0.01 & $\begin{array}{l}\text { SL: } \beta=-0.13, p=0.04 \\
\text { EL: } \beta=0.05, p=0.04 \\
\text { RDAS: } \beta=0.08, p=0.11 \\
\text { SPIN: } \beta=0.06, p=0.23 \\
\text { BDI: } \beta=0.02, p=0.73\end{array}$ \\
\hline Disruptiveness & $5.87(5,515)^{* * *}$ & 0.05 & $\begin{array}{l}\text { SL: } \beta=-0.06, p=0.36 \\
\text { EL: } \beta=0.11, p=0.05 \\
\text { RDAS: } \beta=0.17, p<0.01 \\
\text { SPIN: } \beta=0.01, p=0.81 \\
\text { BDI: } \beta=0.05, p=0.34\end{array}$ & $1.98(5,517)$ & 0.02 & $\begin{array}{l}\text { SL: } \beta=-0.13, p=0.04 \\
\text { EL: } \beta=0.09, p=0.15 \\
\text { RDAS: } \beta=0.07, p=0.15 \\
\text { SPIN: } \beta=0.09, p=0.09 \\
\text { BDI: } \beta=0.01, p=0.79\end{array}$ \\
\hline
\end{tabular}

Each section represents one regression model. Independent variables: social loneliness (SL), emotional loneliness (EL), depression (BDI), social phobia (SPIN), and marital dissatisfaction (RDAS)

$* p \leq 0.05 ; * * \leq 0.01 ; * * p \leq 0.001$

Table 5 Fit statistics of the latent profile analysis

\begin{tabular}{llllll}
\hline $\begin{array}{l}\text { Number of } \\
\text { profiles }\end{array}$ & BIC & AIC & Entropy & Class proportions & Class probabilities \\
\hline 1 & 29734.71 & 29635.11 & 1.00 & 1.00 & 1.00 \\
2 & 26566.86 & 26362.68 & 0.86 & $0.58 / 0.42$ & $0.96 / 0.95$ \\
3 & 25866.78 & 25558.01 & 0.85 & $0.42 / 0.25 / 0.34$ & $0.93 / 0.91 / 0.95$ \\
4 & 25470.39 & 25057.04 & 0.82 & $0.29 / 0.30 / 0.22 / 0.20$ & $0.87 / 0.90 / 0.91 / 0.92$ \\
5 & 25185.07 & 24667.14 & 0.82 & $0.22 / 0.29 / 0.25 / 0.17 / 0.09$ & $0.90 / 0.89 / 0.87 / 0.88 / 0.91$ \\
6 & 25147.25 & 24524.74 & 0.83 & $0.18 / 0.27 / 0.05 / 0.27 / 0.16 /$ & $0.87 / 0.89 / 0.88 / 0.87 / 0.90 /$ \\
& & & & 0.08 & 0.92 \\
\hline
\end{tabular}

significant predicting the cooperating skills of their child ( $p$ s 0.01 and $<0.01$, respectively). When a parent reported higher feelings of social loneliness, the child was evaluated to have poorer cooperating skills. In addition, the empathic behavior of the child was statistically significantly predicted by the reported social loneliness of the mother $(p=0.03)$. The higher marital dissatisfaction of the mothers predicted a higher amount of impulsivity in the child $(p<0.01)$. Additionally, the feelings of social loneliness reported by the father statistically significantly predicted the impulsivity of the child $(p=0.04)$, in the sense that when fathers reported more social loneliness their child was deemed to exhibit less impulsive behavior. A higher amount of emotional loneliness and marital dissatisfaction, as experienced by the mothers, predicted higher amounts of disruptiveness in the children ( $p$ s 0.05 and $<0.01$, respectively). Furthermore, the higher social loneliness of the fathers also predicted a lower level of child disruptiveness.

\section{The Latent Profiles of Parental Psychosocial Well- Being}

Our second aim was to examine the parental psychosocial wellbeing at the family level. In order to accomplish that, the data on the psychosocial well-being measures of both the mothers and the fathers were fitted into an LPA. The model consisted of social and emotional loneliness, depression, social phobia, and the marital dissatisfaction of both mothers and fathers.

The fit indices of the LPA model are presented in Table 5. We selected the five-profile solution based both on the fit 
Fig. 2 Latent profile analysis of parental psychosocial well-being at the 20th week of gestation. (M mother, F father, SL social loneliness, EL emotional loneliness, BDI depressive symptoms, SPIN social phobia, RDAS marital dissatisfaction. All scores are standardized.)

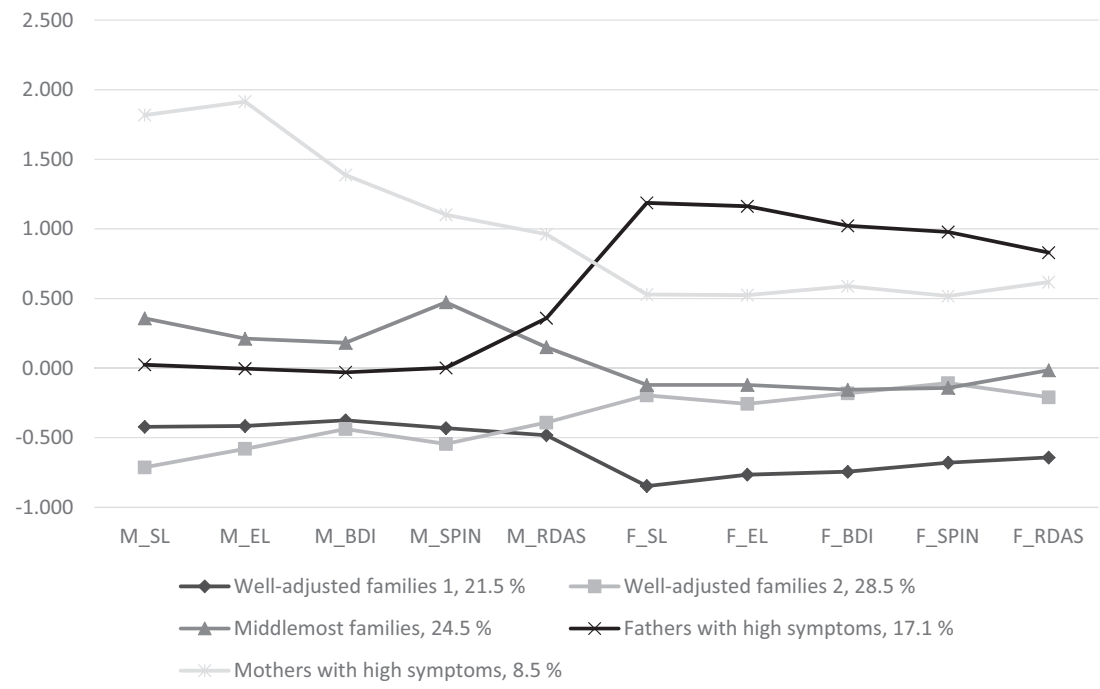

Parents in the last two profiles, Profile 4 and Profile 5, reported having experienced more problems in their psychosocial well-being. In Profile 4, called fathers with high symptoms, the fathers reported more loneliness, depressive symptoms, social phobia, and marital dissatisfaction than the fathers in all the other profiles. At the same time, the mothers experienced no more than average amounts of loneliness, depressive symptoms, social phobia, and marital dissatisfaction. In Profile 5, called mothers with high symptoms, the mothers reported high levels of both social and emotional loneliness, depressive symptoms, social phobia, and marital dissatisfaction. In these families, the fathers scored lower than the mothers, but fathers' scores were still around half a standard deviation above the average on all measures of psychosocial well-being.

\section{The Association Between Family-Level Parental Psychosocial Well-Being and the Social Competence of the Child}

Our third research aim was to study whether the familylevel profiles of parental psychosocial well-being during pregnancy were associated with the social competence of their three-year-old child. To examine this, we added the social competence variables to the LPA as auxiliary variables. Table 6 presents the descriptive statistics of the social competence scores from the different latent profiles of families in addition to the results of these auxiliary analyses. The family-level profiles of parental psychosocial wellbeing during pregnancy did not yield statistically significant differences in the social competence of their three-year-old children, except for impulsivity between well-adjusted families 2 and mothers with high symptoms, $p=0.04$ (other $p \mathrm{~s}>0.05$ ). Additionally, the differences in familylevel psychosocial well-being shown by the LPA also 
Table 6 Descriptive statistics of factors of social competence by latent profiles of families, and the results of the auxiliary analyses

\begin{tabular}{|c|c|c|c|c|c|c|c|c|}
\hline & \multicolumn{2}{|c|}{$\begin{array}{l}\text { Cooperatings- } \\
\text { kills }\end{array}$} & \multicolumn{2}{|c|}{ Empathy } & \multicolumn{2}{|c|}{ Impulsivity } & \multicolumn{2}{|c|}{$\begin{array}{l}\text { Disruptive- } \\
\text { ness }\end{array}$} \\
\hline & $M$ & $S D$ & $M$ & $S D$ & $M$ & $S D$ & $M$ & $S D$ \\
\hline Well-adjusted families 1 & 9.47 & 1.68 & 9.29 & 1.45 & 6.48 & 1.69 & 6.91 & 1.53 \\
\hline Well-adjusted families 2 & 9.64 & 1.62 & 9.55 & 1.54 & 6.40 & 1.47 & 7.09 & 1.71 \\
\hline Middlemost families & 9.45 & 1.42 & 9.34 & 1.53 & 6.33 & 1.68 & 7.01 & 1.78 \\
\hline Fathers with high symptoms & 9.37 & 1.37 & 9.31 & 1.36 & 6.48 & 1.68 & 7.15 & 1.79 \\
\hline Mothers with high symptoms & 9.20 & 1.36 & 9.11 & 1.35 & 6.98 & 1.74 & 7.47 & 1.96 \\
\hline$p$ value & 0.39 & & 0.35 & & 0.27 & & 0.47 & \\
\hline
\end{tabular}

$p$ values were calculated by adding the four MASCS factors as auxiliary variables to the latent profile analysis. In pairwise comparisons, the differences were not statistically significant, except in impulsivity between well-adjusted families 2 and mothers with high symptoms $(p=0.04)$ remained quite stable over a two-year period, beginning during pregnancy and ending when the child was 18 months old.

\section{Discussion}

The main aim of this research was to analyze how parental psychosocial well-being during pregnancy predicted the social competence of their three-year-old child. In the current study, parental psychosocial well-being consisted of experiences of social and emotional loneliness, depressive symptoms, social phobia, and marital dissatisfaction.

Our first research aim focused on the parent-child level, specifically examining if problems in the psychosocial wellbeing of one parent predicted lower levels in the social competence of their child. According to our results, parental loneliness was an especially important element in the sense that a higher experience of loneliness was related to lower levels in the future prosocial competence of the child. This was in line with our hypothesis of dyadic relations between the psychosocial well-being of one parent and the social development of their child. More critically, the higher social loneliness of both the mothers and the fathers resulted in their children having poorer cooperating skills. Drawing from Solomon (2000) and Hawkley et al. (2003), the poorer cooperating skills of the children could be affected by a higher level of parental loneliness that causes the parents to withdraw from social interactions. Due to this, the children may have fewer opportunities to practice their prosocial skills and behavior (Lawhon 1997).

According to our results, higher marital dissatisfaction, expressed by the mothers, predicted higher scores on impulsivity and disruptiveness in the children. This was consistent with the study by Zhou et al. (2017), which found that inter-parental conflict was directly associated with externalizing problems in two-year-old children.

Our second aim was to investigate the psychosocial wellbeing of the mothers and the fathers together in order to gain knowledge about their psychosocial well-being at the family level. The results of the LPA demonstrate that, even when one parent reported high levels of loneliness, depressive symptoms, social phobia, and marital dissatisfaction, the other parent in the family produced average scores on the same measures. One exception was the scores for marital dissatisfaction, which implied that when one parent experienced problems in their psychosocial wellbeing, both parents seemed to be more dissatisfied with the marital relationship as compared to the parents in the other three profiles. Thus, the poorer experience of the reported psychosocial well-being of one parent seemed to result in higher levels of marital dissatisfaction in both parents. This is consistent with an earlier study, in which up to $40 \%$ of the variance in the quality of the marital relationship was explained by emotional loneliness (Knoke et al. 2010). This result aligned with Stone and Shackelford (2006), who argued that the emotional instability of the spouse correlates with one's own marital dissatisfaction. Despite the effects on marital dissatisfaction, even though one parent experienced problems in their psychosocial well-being, the other parent seemed to cope better.

Our third aim was to study whether these family level profiles of psychosocial well-being were associated with the social competence of their three-year-old child. The results revealed that the family-level profile of parental psychosocial well-being did not have a statistically significant association with the future social competence of the child. Therefore, despite the fact that one parent reported problems in their psychosocial well-being, it can be assumed that the relatively better psychosocial well-being of the other parent seems to have acted as a protective element for the developing social competence of the child. This result does not align with our hypothesis, since we expected to see a profile of families in which both parents reported problematic psychosocial well-being, and we assumed to see these children being affected by the family-level profile of psychosocial well-being. Nevertheless, we consider this as a positive and very hopeful result. These results can also be 
viewed through the broader perspective of social learning. Despite the problematic psychosocial well-being of the other parent, the parent reporting better psychosocial wellbeing could have modeled enough positive behavior for the child to support the social development of the child (e.g., Bandura 1963; Bandura and Walters 1963). These results are also consistent with Goodman et al.'s (2011) notion that a healthy father can support the healthy development of the child when the mother experiences depression.

These differences in family-level psychosocial wellbeing, which were found in the LPA, were also statistically significant in the following two years, beginning during pregnancy and ending when the child was 18 months old. This indicates that variations in parental psychosocial wellbeing in the five profiles of families occurred during the early childhood years, not only during pregnancy. Thus, it is crucial to identify the parents and families who need help and to support them during maternity clinic visits or, at the latest, during checkups at child health clinics.

One of the strengths of our research was the use of validated measurement scales, as well as the longitudinal research design. Additionally, the study combined the family-level psychosocial well-being of both mothers and fathers, which is a less common research focus. In addition, to our knowledge there is very little research that combines all these phenomena of parental psychosocial well-being.

\section{Limitations}

One limitation of this study was that the social competence of the children was rated only by the parents. This could cause skewed evaluations in families in which parents experienced problems in their psychosocial well-being. Since loneliness is related to negative evaluations of others (see Spithoven et al. 2017, for a review), and since depression is related to a greater attentional bias towards negative information (Peckham et al. 2010; Everaert et al. 2012), in our study the parents who reported problems in their psychosocial well-being may have manifested their cognitive biases by evaluating their child as behaving more problematically and being less skillful. Naturally, based on our analyses, it is not possible to say if the development of the social competence of the children was negatively affected by the parental psychosocial well-being or if the assessments of social competence were affected by cognitive biases of the parents.

Another limitation of the study is that the number of participants dropped over time, which is characteristic of follow-up studies. The sample size dropped from 1075 families at the first measurement point to 651 families at the second measurement point. The lack of control variables in the analyses can also be considered as a limitation of our study.
In contrast to our hypothesis, we did not find a profile of families in which both parents reported problems in their psychosocial well-being. Furthermore, it must be noted that, when using LPA, the goal is to find the smallest number of latent profiles. Therefore, in our sample, there might be families in which both parents experienced problems in their psychosocial well-being even though there is no such profile of families in the presented results. Fortunately, this group of families must be relatively small because no such profile became observable in our analyses.

\section{Implications}

As practical implications of our study, the results can be seen as supporting the continuity of care from maternity clinics to child health clinics and to early childhood education and care. Previous studies in Finland have raised the need to combine maternity clinics and child health clinics, so that the same public health nurse would continue working with the family from the period of pregnancy to the last child health clinic visit when the child is 6 years old, to enable the continuity of care in order to support the well-being of families (e.g., Honkanen 2008; Tuominen et al. 2016). This continuity would make it possible for the parents to develop a close relationship with the public health nurse. The closer relationship between the public health nurse and the parents would support a safe atmosphere to safely discuss the potential psychosocial problems in the family (Honkanen 2008; Tammentie et al. 2009).

At the policy level, the results of our study enhance the need to develop the processes regarding the identification of parental psychosocial problems in maternal healthcare and child healthcare, as well as early childhood education and care. Recently, the Finnish government launched their preparations for a National Child Strategy. In their report, emphasis is put on developing strategies to tackle the psychosocial problems of families and to support parenthood already during pregnancy (Enabling Growth, Learning and Inclusion for All, 2019). Based on our results, serious efforts should be made on a societal level to enhance the psychosocial well-being of parents and to reduce the negative effects the parental psychosocial problems have for the social development of young children.

In future empirical studies, the interrelations between parental psychosocial well-being and the development of the social competence of their children should be explored in greater depth. While our study offered new information about the interrelations between parental psychosocial wellbeing during pregnancy and the early social competence of the child, these associations should be studied further. The social competence of children should be evaluated with a multisource assessment that collects data from parents and 
from early childhood educators as well as self-assessments from the children themselves when they are older (e.g., Junttila et al. 2006). The social competence of children should also be examined in a longitudinal setting. Since social competence develops rapidly during the childhood years, it would be advantageous to account for changes in the social competence of children over time. In addition, broadening the scope of future studies by examining parenting practices could yield additional information about how parents function while rearing their child. This would broaden the view from simply psychosocial well-being to a more comprehensive view of families.

\section{Conclusion}

Our results reveal that if even one parent experiences positive psychosocial well-being, this parent can support the well-being and social development of their child. The theory of social learning explains that children learn new skills by watching adults doing tasks and navigating social events. Though one parent experiences problems in his/her psychosocial well-being and models problematic social behavior, the positive psychosocial well-being of the other parent in the family may produce enough favorable positive adult behavior for the child to see, therefore protecting the development of the social competence of the child. One practical implication, which can be incorporated when working with parents and their children, is to focus on the big picture: parental psychosocial well-being should be examined at the family level and the well-being of both mothers and fathers should be considered. This could occur at maternity clinics or later at child health clinics and at school healthcare. The professionals working in maternity clinics could then identify the parents and families with potentially problematic psychosocial profiles. These health professionals could then seek ways to support the psychosocial well-being of both parents already during pregnancy, and by first supporting the parents, the professionals and parents could work together towards creating a more stable environment for the positive social development of the child.

Acknowledgements Open access funding provided by University of Turku (UTU) including Turku University Central Hospital.

Funding This study was funded by Turku University Foundation (grant number 13681, funding granted to Venla Panula).

\section{Compliance with ethical standards}

Conflict of interest The authors declare that they have no conflict of interest.
Publisher's note Springer Nature remains neutral with regard to jurisdictional claims in published maps and institutional affiliations.

Open Access This article is licensed under a Creative Commons Attribution 4.0 International License, which permits use, sharing, adaptation, distribution and reproduction in any medium or format, as long as you give appropriate credit to the original author(s) and the source, provide a link to the Creative Commons license, and indicate if changes were made. The images or other third party material in this article are included in the article's Creative Commons license, unless indicated otherwise in a credit line to the material. If material is not included in the article's Creative Commons license and your intended use is not permitted by statutory regulation or exceeds the permitted use, you will need to obtain permission directly from the copyright holder. To view a copy of this license, visit http://creativecommons. org/licenses/by/4.0/.

\section{References}

Accortt, E. E., Cheadle, A. C. D., \& Dunkel Schetter, C. (2015). Prenatal depression and adverse birth outcomes: an updated systematic review. Maternal Child and Health Journal, 19(6), 1306-1337. https://doi.org/10.1007/s10995-014-1637-2.

Ahlqvist-Björkroth, S. (2017). Challenges for the transition into early parenthood: Prenatal depressive symptoms, marital distress, and the premature birth of an infant. Annales Universitatis Turkuensis, Series B, Pt. 438. Turku: University of Turku.

Akaike, H. (1987). Factor analysis and AIC. Psychometrika, 52, 317-332.

Aldercotte, A., White, N., \& Hughes, C. (2016). Sibling and peer relationships in early childhood. In L. Balter \& C. S. TamisLeMonda (Eds), Child psychology: a handbook of contemporary issues (pp. 141-165). 3rd ed. New York: Routledge.

Anderson-Butcher, D., Iachini, A. L., \& Amorose, A. J. (2008). Initial reliability and validity of the Perceived Social Competence Scale. Research on Social Work Practice, 18, 47-54. https://doi.org/10. 1177/1049731507304364.

Bandura, A. (1963). Behavior theory and identificatory learning. American Journal of Orthopsychiatry, 33(4), 591-601.

Bandura, A., \& Walters, R. H. (1963). Social learning and personality development. New York: Holt Rinehart and Winston.

Beck, A. T., Brown, G., \& Steer, R. A. (1996). Beck depression inventory II: Manual. San Antonio, TX: The Psychological Corporation.

Beck, C. T. (2001). Predictors of postpartum depression: an update. Nursing Research, 50, 275-285.

Burt, K. B., Obradovic, J., Long, J. D., \& Masten, A. S. (2008). The interplay of social competence and psychopathology over 20 years: testing transactional and cascade models. Child Development, 79, 359-374. https://doi.org/10.1111/j.1467-8624.2007.01130.x.

Busby, D. M., Cristensen, C., Grane, D. R., \& Larson, J. H. (1995). A revision of the dyadic adjustment scale for use with distressed and nondistressed couples: construct hierarchy and multidimensional scales. Journal of Marital and Family Therapy, 21, 289-308.

Connor, K. M., Davidson, J. R. T., Churchill, L. E., Sherwood, A., Foa, E., \& Weisler, R. H. (2000). Psychometric properties of the Social Phobia Inventory (SPIN). New self-rating scale. The British Journal of Psychiatry, 176, 379-386. https://doi.org/10. 1192/bjp.176.4.379.

Crosby Budinger, M., Drazdowski, T. K., \& Ginsburg, G. S. (2013). Anxiety-promoting parenting behaviors: a comparison of anxious parents with and without social anxiety disorder. Child Psychiatry 
and Human Development, 44, 412-418. https://doi.org/10.1007/ s10578-012-0335-9.

DiTommaso, E., \& Spinner, B. (1997). Social and emotional loneliness: a re-examination of Weiss' typology of loneliness. Personality and Individual Differences, 22(3), 417-427. https://doi. org/10.1016/S0191-8869(96)00204-8.

Dix, T. (1991). The affective organization of parenting: adaptive and maladaptive processes. Psychological Bulletin, 110, 3-25.

Dix, T., \& Yan, N. (2014). Mothers' depressive symptoms and infant negative emotionality in the prediction of child adjustment at age 3 : testing the maternal reactivity and child vulnerability hypotheses. Development and Psychopathology, 26, 111-124. https:// doi.org/10.1017/S0954579413000898.

Enabling Growth, Learning and Inclusion for All (2019). Research findings and recommendations for promoting children and young people's opportunities for balanced growth, health and impact. Publications of the Finnish Government. Ministry of Education and Culture, Ministry of Social Affairs and Health, Helsinki.

Everaert, J., Koster, E. H. W., \& Derakshan, N. (2012). The combined cognitive bias hypothesis in depression. Clinical Psychology Review, 32(5), 413-424. https://doi.org/10.1016/j.cpr.2012.04. 003.

Field, T. (2017). Prenatal depression risk factors, developmental effects and interventions: a review. Journal of Pregnancy and Child Health 4(1). https://doi.org/10.4172/2376-127X.1000301

Field, T. (2011). Prenatal depression effects on early development: a review. Infant Behavior \&. Development, 34(1), 1-14. https://doi. org/10.1016/j.infbeh.2010.09.008.

Gariépy, J.-F., Watson, K. K., Du, E., Zie, D. L., Erb, J., Amasino, D. \& Platt, M. L. (2014). Social learning in humans and other animals. Frontiers in Neuroscience 8. https://doi.org/10.3389/fnins.2014. 00058

Gentile, S., \& Fusco, M. L. (2017). Untreated perinatal paternal depression: effects of offspring. Psychiatry Research, 252, 325-332. https://doi.org/10.1016/j.psychres.2017.02.064.

Gere, M. K., Hagen, K. A., Villabø, M. A., Arnberg, K., Neumer, S. P., \& Torgersen, S. (2013). Fathers' mental health as a protective factor in the relationship between maternal and child depressive symptoms. Depression and Anxiety, 30, 31-38. https://doi.org/10. 1002/da.22010.

Goodman, S. H., Rouse, M. H., Connell, A. M., Broth, M. R., Hall, C. M., \& Heyward, D. (2011). Maternal depression and child psychopathology: a meta-analytic review. Clinical Child and Family Psychology Review, 14, 1-27. https://doi.org/10.1007/s10567010-0080-1.

Hagerty, B., \& Williams, A. (1999). The effects of sense of belonging, social support, conflict and loneliness on depression. Nursing Research, 48, 215-219. https://doi.org/10.1097/00006199199907000-00004.

Hawkley, L. C., Burleson, M. H., Berntson, G. G., \& Cacioppo, J. T. (2003). Loneliness in everyday life: cardiovascular activity, psychosocial context, and health behaviors. Journal of Personality and Social Psychology, 85, 105-120. https://doi.org/10. 1037/0022-3514.85.1.105.

Hawkley, L., Hughes, M., Waite, L., Masi, C., Thisted, R., \& Cacioppo, J. (2008). From social structural factors to perceptions of relationship quality and loneliness: the Chicago health, aging, and social relations study. The Journals of Gerontology, Series B, Psychological Sciences and Social Sciences, 63, S375-S384. https://doi.org/10.1093/geronb/63.6.S375.

Hay, D. F., \& Cook, K. V. (2007). The transformation of prosocial behavior from infancy to childhood. In C. A. Brownell \& C. B. Kopp (Eds), Socioemotional development in the toddler years (pp. 100-131). New York: The Guilford Press.
Heinrich, L. M., \& Gullone, E. (2006). The clinical significance of loneliness: a literature review. Clinical Psychology Review, 26(6), 695-718. https://doi.org/10.1016/j.cpr.2006.04.002.

Hojat, M. (1982). Psychometric characteristics of the UCLA loneliness scale: a study with Iranian college students. Educational and Psychological Measurement, 42, 917-925. https://doi.org/10. 1177/001316448204200328.

Honkanen, H. (2008). Family at risk in the context of maternity and child welfare clinic. Mental health promotion as a point of view. Kuopio University Publications, Series E. Social Sciences, Pt. 160. Kuopio: Kuopio University.

Hoza, B., Bukowski, W. M., \& Beery, S. (2000). Assessing peer network and dyadic loneliness. Journal of Clinical Child Psychology, 29, 119-128. https://doi.org/10.1207/S15374424jccp2901_12.

Jacobs, R. H., Talati, A., Wickramaratne, P., \& Warner, V. (2015). The influence of paternal and maternal major depressive disorder on offspring psychiatric disorders. Journal of Child and Family Studies, 24, 2345-2351. https://doi.org/10.1007/s10826-0140037-y.

Junttila, N. (2010). Social competence and loneliness during the school years-issues in assessment, interrelations and intergenerational transmission. Annales Universitatis Turkuensis, Serie B, Pt. 325. Turku: University of Turku.

Junttila, N., Ahlqvist-Björkroth, S., Aromaa, M., Rautava, P., Piha, J., \& Räihä, H. (2015a). Intercorrelations and developmental pathways of mothers' and fathers' loneliness during pregnancy, infancy and toddlerhood-STEPS study. Scandinavian Journal of Psychology, 56(5), 482-488. https://doi.org/10.1111/sjop. 12241.

Junttila, N., Aromaa, M., Rautava, P., Piha, J., \& Räihä, H. (2015b). Measuring multidimensional parental self-efficacy of mothers and fathers of children aged 1.5 and 3 years. Family Relations, 64(5), 665-680. https://doi.org/10.1111/fare.12161.

Junttila, N., Ahlqvist-Björkroth, S., Aromaa, M., Rautava, P., Piha, J., Vauras, M., \& Räihä, H. (2013). Mothers' and fathers' loneliness during pregnancy, infancy and toddlerhood. Psychology and Education, 50, 98-104.

Junttila, N., \& Vauras, M. (2009). Loneliness among school-aged children and their parents. Scandinavian Journal of Psychology, 50, 211-219.

Junttila, N., Voeten, M., Kaukiainen, A., \& Vauras, M. (2006). Multisource assessment of children's social competence. Educational and Psychological Measurement, 66, 874-895. https://doi.org/10. 1177/0013164405285546.

Kertz, S. J., Smith, C. L., Chapman, L. K., \& Woodruff-Borden, J. (2008). Maternal sensitivity and anxiety: impacts on child outcome. Child \& Family Behavior Therapy, 30, 153-171. https:// doi.org/10.1080/07317100802060336.

Knoke, J., Burau, J., \& Roehrle, B. (2010). Attachment styles, loneliness, quality, and stability of marital relationships. Journal of Divorce \& Remarriage, 51, 310-325. https://doi.org/10.1080/ 10502551003652017.

Korja, R., Piha, J., Otava, R., Lavanchy-Scaiola, C., Ahlqvist-Björkroth, S., \& Aromaa, M., STEPS study. (2016). Mother's marital satisfaction associated with the quality of mother-father-child triadic interaction. Scandinavian Journal of Psychology, 57, 305-312. https://doi.org/10.1111/sjop.12294.

Lagström, H., Rautava, P., Kaljonen, A., Räihä, H., Pihlaja, P., Korpilahti, P., \& Niemi, P. (2013). Cohort profile: steps to the healthy development and well-being of children (the STEPS study). International Journal of Epidemiology, 42, 1203-1210. https:// doi.org/10.1093/ije/dys150.

Lawhon, T. (1997). Encouraging friendships among children. Childhood Education, 73(4), 228-231. https://doi.org/10.1080/ 00094056.1997.10521099. 
McWhirter, B. T. (1990). Factor analysis of the revised UCLA loneliness scale. Current Psychology, 9, 56-68. https://doi.org/10. 1007/BF02686768.

Montgomery, D. C., Peck, E. A., \& Vining, G. G. (2012). Introduction to linear regression analysis. Hoboken, New Jersey: John Wiley $\&$ Sons Inc.

Muthén, L. K., \& Muthén, B. O. (2013). Mplus version 7. Statistical analysis with latent variables. Los Angeles: Muthén \& Muthén.

Muyan, M., Chang, E., Jilani, Z., Yu, T., Lin, J., \& Hirsch, J. (2016). Loneliness and negative affective conditions in adults: is there any room for hope in predicting anxiety and depressive symptoms?. Journal of Psychology, 150, 333-341. https://doi.org/10. 1080/00223980.2015.1039474.

NICHD Early Childcare Research Network. (1999). Chronicity of maternal depressive symptoms, maternal sensitivity, and child functioning at 36 months. Developmental Psychology, 35, 1297-1310. https://doi.org/10.1037/0012-1649.35.5.1297.

Nolen-Hoeksema, S., \& Ahrens, C. (2002). Age differences and similarities in the correlates of depressive symptoms. Psychology and Aging, 17, 116-124. https://doi.org/10.1037/0882-7974.17.1. 116.

Nolvi, S., Karlsson, L., Bridgett, D. J., Korja, R., Huizink, A. C., Kataja, E.-L., \& Karlsson, H. (2016). Maternal prenatal stress and infant emotional reactivity six months postpartum. Journal of Affective Disorders, 199, 163-170. https://doi.org/10.1016/j.jad. 2016.04.020.

O'Connor, T. G., Heron, J., Golding, J., Beveridge, M., \& Glover, V. (2002). Maternal antenatal anxiety and children's behavioural/ emotional problems at 4 years: report from the Avon Longitudinal Study of Parents and Children. British Journal of Psychiatry, 180, 502-508.

Paulson, J., Bazemore, S., Goodman, J., \& Leiferman, J. (2016). The course and interrelationship of maternal and paternal perinatal depression. Archives of Women's Mental Health, 19, 655-663. https://doi.org/10.1007/s00737-016-0598-4.

Peckham, A. D., McHugh, R. K., \& Otto, M. W. (2010). A metaanalysis of the magnitude of biased attention in depression. Depression and Anxiety, 27, 1135-1142. https://doi.org/10.1002/ da.20755.

Pretorius, T. B. (1993). The metric equivalence of the UCLA loneliness scale for a sample of South African students. Educational and Psychological Measurement, 53, 233-239. https://doi.org/10. 1177/0013164493053001026.

Ranta, K. (2008). Social phobia among Finnish adolescents: assessment, epidemiology, comorbidity, and correlates. Tampere: Tampere University Press.

Richards, D. (2011). Prevalence and clinical course of depression: a review. Clinical Psychology Review, 31(7), 1117-1125. https:// doi.org/10.1016/j.cpr.2011.07.004.

Rose-Krasnor, L., \& Denham, S. (2009). Social-emotional competence in early childhood. In K. H. Rubin, W. M. Bukowski, \& B. Laursen (Eds), Handbook of peer interactions, relationships, and groups (pp. 162-179). New York: The Guilford Press.

Rotenberg, K. J. (1999). Childhood and adolescent loneliness: an introduction. In K. J. Rotenberg, \& S. Hymell (Eds), Loneliness in childhood and adolescence (pp. 3-8). Cambridge: Cambridge University Press.

Rubin, K. H., Bukowski, W. M., \& Parker, J. G. (2006). Peer interactions, relationships, and groups. In W. Damon, R. M. Lerner, \& N. Eisenberg (Eds), Handbook of child psychology (6th ed., Vol. 3, pp. 571-645). New York: Wiley.

Russell, D., Peplau, L. A., \& Cutrona, C. E. (1980). The revised UCLA Loneliness Scale: concurrent and discriminant validity evidence. Journal of Personality \& Social Psychology, 39, $472-480$.

Seimyr, L., Sjögren, B., Welles-Nyström, B., \& Nissen, E. (2009). Antenatal maternal depressive mood and parental-fetal attachment at the end of pregnancy. Archives of Women's Mental Health, 12, 269-279. https://doi.org/10.1007/s00737-009-0079-0.

Solomon, S. M. (2000). Childhood loneliness: implications and intervention considerations for family therapists. The Family Journal: Counseling and Therapy for Couples and Families, 8, 161-164. https://doi.org/10.1177/1066480700082008.

Spithoven, A. W. M., Bijttebier, P., \& Goossens, L. (2017). It is all in their mind: a review on information processing bias in lonely individuals. Clinical Psychology Review, 58, 97-114. https://doi. org/10.1016/j.cpr.2017.10.003.

Stone, E. A. \& Shackelford, T. K. (2006). Marital satisfaction. In R. F. Baumeister \& K. D. Vohs (Eds), Encyclopedia of Social Psychology. Thousand Oaks, CA: Sage.

Tammentie, T., Paavilainen, E., Tarkka, M., \& Åstedt-Kurki, P. (2009). Families' experiences of interaction with the public health nurse at the child health clinic in connection with mother's postnatal depression. Journal of Psychiatric and Mental Health Nursing, 16(8), 716-724. https://doi.org/10.1111/j.1365-2850. 2009.01448.x.

Tremblay, R. E. (2005). Aggressive and prosocial behavior. In B. Hopkins, R. G. Barr, G. F. Michel, \& P. Rochat (Eds). The Cambridge Encyclopedia of Child Development. Cambridge: Cambridge University Press.

Tuominen, M., Junttila, N., Ahonen, P., \& Rautava, P. (2016). The effect of relational continuity of care in maternity and child health clinics on parenting self-efficacy of mothers and fathers with loneliness and depressive symptoms. Scandinavian Journal of Psychology, 57, 193-200. https://doi.org/10.1111/sjop.12284.

Vakrat, A., Apter-Levy, Y., \& Feldman, R. (2018). Sensitive fathering buffers the effects of chronic maternal depression on child psychopathology. Child Psychiatry \& Human Development, 49, 779-785. https://doi.org/10.1007/s10578-018-0795-7.

Victor, C., \& Yang, K. (2012). The prevalence of loneliness among adults: a case study of the United Kingdom. The Journal of Psychology, 146, 85-104. https://doi.org/10.1080/00223980. 2011.613875.

Vygotsky, L. S. (1978). Mind in society. The development of higher psychological processes. Cambridge, MA: Harvard University Press.

Wang, M., \& Bodner, T. E. (2007). Growth mixture modelling: identifying and predicting unobserved subpopulations with longitudinal data. Organizational Research Methods, 10, 635-656. https://doi.org/10.1177/1094428106289397.

Wang, Y., \& Dix, T. (2015). Mothers' early depressive symptoms predict children's low social competence in first grade: Mediation by children's social cognition. Journal of Child Psychology and Psychiatry, 56, 183-192. https://doi.org/10.1111/jcpp.12297.

Weiss, R. S. (1973). Loneliness: the experience of emotional and social isolation. Massachusetts: The MIT Press.

Wertsch, J. V. (1985). Vygotsky and the social formation of mind. Massachusetts: Harvard University Press.

Whisman, M. A. (1999). Marital dissatisfaction and psychiatric disorders: results from the national comorbidity survey. Journal of Abnormal Psychology, 108(4), 701-706. https://doi.org/10.1037/ 0021-843X.108.4.701.

White, M. B., Stahmann, R. F., \& Furrow, J. L. (1994). Shorter may be better: a comparison of the Kansas Marital Satisfaction Scale and the Locke-Wallace Marital Adjustment Test. Family Perspective, $28,53-66$ 
Williamson, R. A., Donohue, M. R., \& Tully, E. C. (2013). Learning how to help others: Two-year-olds' social learning of a prosocial act. Journal of Experimental Child Psychology, 114(4), 543-550. https://doi.org/10.1016/j.jecp.2012.11.004.

Wilson, S., \& Durbin, C. E. (2010). Effects of paternal depression on fathers' parenting behaviors: a meta-analytic review. Clinical
Psychology Review, 30(2), 167-180. https://doi.org/10.1016/j. cpr.2009.10.007.

Zhou, N., Cao, H., \& Leerkes, E. M. (2017). Interparental conflict and infants' behavior problems: the mediating role of maternal sensitivity. Journal of Family Psychology, 31, 464-474. https://doi. org/10.1037/fam0000288. 